\title{
Effect of Oxygen on the Burning Behavior of Liquid and Solid Fuels in a Large-Scale Calorimeter
}

\author{
D. Alibert ${ }^{1 \dagger}$, M. Coutin ${ }^{2}$, M. Mense ${ }^{2}$, Y. Pizzo ${ }^{1}$ and B. Porterie ${ }^{1}$ \\ ${ }^{I}$ Aix-Marseille University (AMU), CNRS, IUSTI UMR 7343, 13453 Marseille, France \\ ${ }^{2}$ Institute of Radiation Protection and Nuclear Safety (IRSN), PSN-RES, SA2I, Cadarache, 13115 Saint-Paul- \\ Lez-Durance, France
}

†Corresponding Author Email:david.alibert@univ-amu.fr

(Received April 21, 2018; accepted June 11, 2018)

\begin{abstract}
The purpose of this experimental study was two-fold: first, to explore and understand the effects of oxygen availability on the combustion of liquid and solid fuels; second, to provide data for comparison with CFD models. Experiments were conducted in the controlled-atmosphere calorimeter of IRSN, called CADUCEE, varying the oxygen concentration in the oxidizing stream and the size of the fire. Polymethylmethacrylate (PMMA) and heptane were used as fuels. Results are found to be in good agreement with the literature data. As the oxygen level decreases, the mass loss rate and flame heat feedback decrease, as well as the flame height and maximum flame temperature, for both fuels whatever the sample size. For heptane pool fires, temperature measurements in the liquid layer reveal a decrease in heat transfer at the fuel surface and inside the fuel with the oxygen molar fraction. For PMMA, the radiative and convective contributions to the total heat flux remain nearly constant, with about $65 \%$ and $35 \%$ respectively, regardless of sample size and oxygen concentration.
\end{abstract}

Keywords: Fire; Pool fires; Pyrolysis; PMMA; Heptane; Calorimeter.

\section{NOMENCLATURE}

$\begin{array}{ll}B & \text { Spalding mass transfer number } \\ c & \text { convective } \\ c p & \text { condensed phase } \\ c_{p} & \text { specific heat at constant pressure } \\ D & \text { pan diameter } \\ e & \text { external } \\ f & \text { flame } \\ g & \text { gas } \\ h_{c} & \text { convective transfer coefficient } \\ k & \text { extinction coefficient } \\ l & \text { loss } \\ L_{G} & \text { heat of gasification } \\ \dot{m}^{\prime \prime} & \text { mass loss rate per unit of area } \\ O_{2} & \text { oxygen } \\ r & \text { radiative } \\ r & \text { stoichiometric oxygen to fuel mass ratio } \\ s & \text { surface }\end{array}$

\section{INTRODUCTION AND CONTEXT}

The effect of oxygen on fuel combustion is of primary importance for fire safety, especially in mechanically-ventilated compartments such as in a nuclear power plant. The amount of oxygen

$\begin{array}{ll}T & \text { temperature } \\ t & \text { total } \\ X & \text { molar fraction } \\ Y & \text { mass fraction } \\ & \\ \infty & \text { ambient } \\ \beta & \text { blocking factor } \\ \varepsilon & \text { emissivity } \\ \eta & \text { Nasr model parameter } \\ \alpha & \text { Nasr model parameter } \\ \sigma & \text { Stefan-Boltzmann constant } \\ \xi & \text { Tewarson empirical parameter } \\ \Delta h & \text { heat of combustion } \\ \chi_{r} & \text { flame radiative fraction } \\ \dot{q}^{\prime \prime} & \text { heat flux per unit of area } \\ 21 & \text { 21\% oxygen concentration }\end{array}$

available for combustion depends mainly on the rate at which replacement air can enter the compartment, due to either natural of forced ventilation. During the fire growth period, when the air supply is not large enough to completely feed the flame, the fire becomes ventilation controlled. A 
decrease in the heat feedback from the flame to the fuel surface can be observed, which in turn leads to a decrease in Mass Loss Rate (MLR). This is accompanied by changes in other properties, such as the regression rate of the fuel surface, gas temperature and composition, and heat feedback to the fuel surface.

A model developed by Utiskul et al. (2005) may be used to express the MLR as a function of the oxygen molar fraction. This model is based on the Quintiere approach (Quintiere and Rangwala 2004) and some simplifying assumptions. By assuming a small transfer number (called B number, see the definition below) and neglecting the flame radiative effects, Utiskul et al. (2005) obtained the following relationship:

$\dot{m}^{\prime \prime}=\dot{m}_{21}^{\prime \prime} \frac{X_{O_{2}}}{0.21}+\frac{\dot{q}_{e, r}^{\prime \prime}}{L_{G}}$

More recently, Nasr et al. (2011) developed a model to determine the fuel MLR in a mechanically-ventilated confined compartment using a global method. This model is based on an energy balance at the fuel surface considering the radiative flux emitted by the flame and nonnegligible mass transfer number $\mathrm{B}$

$$
\begin{aligned}
\dot{m}_{F}^{\prime \prime} L_{G} & =\frac{h_{c} \ln (1+B)}{c_{p} B}\left[Y_{O 2} \frac{\Delta h}{r}\left(1-\chi_{r}\right)-c_{p}\left(T_{s}-T_{\infty}\right)\right] \\
& +\sigma \varepsilon_{f}\left(\alpha Y_{O_{2}}+\eta\right)^{4}+\sigma\left(1-\varepsilon_{f}\right)\left(T_{g}^{4}-T_{s}^{4}\right)- \\
& \sigma\left(T_{s}^{4}-T_{\infty}^{4}\right)
\end{aligned}
$$

with $B=\left[Y_{O 2} \frac{\Delta h}{r}-c_{p}\left(T_{s}-T_{\infty}\right)\right] / L_{G}$.

Tewarson and Pion (1976) determined the MLR of a large variety of solid and liquid fuels from smallscale experiments varying the oxygen concentration. For a wide range of oxygen concentration values, they expressed the MLR as a linear function of the oxygen concentration for all the fuels studied:

$$
\dot{m}^{\prime \prime}=\frac{\xi}{L_{G}} X_{O_{2}}+\frac{\dot{q}_{e, r}^{\prime \prime}-\dot{q}_{l}^{\prime \prime}}{L_{G}}
$$

Compartment fire experiments were performed by Peatross and Beyler (1997) using either natural or overhead forced ventilation to assess the effect of ventilation on the compartment fire environment. The ventilation rate was varied by changing the vent size in natural ventilation tests and mechanically in forced ventilation tests. Three fuels were used: diesel fuel, wood cribs, and polyurethane slabs. For naturally ventilated fires, it was noted that the vent size and geometry had a significant impact on the vertical temperature and oxygen concentration profiles. Both the temperature and oxygen concentration measurements were representative of two-layer environments. However, in terms of oxygen concentration, forced ventilation fires resulted in a well-mixed compartment regardless of the ventilation rate. In contrast, temperature measurements showed either a twolayer or linear variation with respect to compartment height, depending on the scenario. The authors showed that reduced oxygen concentrations at the flame base resulted in reduced mass loss rates. The relationship between these burning rates and the oxygen concentration at the flame base was examined, and a correlation was developed. Including data from Tewarson et al. (1981) and Santo and Tamanini (1981), Peatross and Beyler (1997) found a linear correlation between the MLR and the molar fraction of oxygen

$$
\frac{\dot{m}^{\prime \prime}}{\dot{m}_{21}^{\prime \prime}}=10 X_{O_{2}}-1.1
$$

This correlation gave a good agreement with experimental results on a small scale, from 0.007 to $0.07 \mathrm{~m}^{2}$, and on a larger scale, from 0.3 to $0.55 \mathrm{~m}^{2}$, for diesel, heptane and PMMA.

In this context, the present study aims to analyze the effect of oxygen depletion on the combustion of horizontal PMMA slabs and heptane pools. While many studies have been conducted on the combustion of vertically-oriented and tilted slabs of PMMA (e.g. Pizzo et al., 2009; Chen et al., 2015; Drysdale and MacMillan 1992; Gollner et al., 2013), very few have been on horizontal configurations and even less in under-ventilated conditions. Rhodes and Quintiere (1996) conducted cone calorimeter tests to evaluate the mass loss rate and heat flux at the surface of horizontal black PMMA slabs. Linteris et al. (2005) have also studied the combustion of black PMMA on a small scale, under cone calorimeter, but for both horizontal and vertical configurations. Beaulieu and Dembsey (2008) conducted bench scale horizontal and single wall vertical orientation experiments for black PMMA, propylene gas and black polyoxymethylene to directly quantify the effects of enhanced ambient oxygen concentration on the flame heat flux. They provided a good explanation of what enhanced ambient oxygen concentration is doing in terms of flame temperature, soot concentration, and thus heat flux. We can also mention the works of Kacem et al. (2016) who performed free-burning experiments using square PMMA slabs with sides of 10,20 and $40 \mathrm{~cm}$.

Regarding liquid fuel combustion, many studies have been conducted on the subject in recent decades, owing to its high heat of combustion. A lot of experimental studies have been carried out, varying the pool size, the lip, size and material of the pan, the initial fuel layer, the initial fuel temperature, to name but a few examples. They showed a larger scatter in the reported data, especially those concerning the pyrolysis rate Following Zabetakis and Burgess (1961) the following relationship can be used to represent the burning rate per unit area as a function of pool diameter, $\mathrm{D}$ :

$\dot{m}^{\prime \prime}=\dot{m}_{\max }^{\prime \prime}[1-\exp (-k \beta D)]$ 
where $k$ is the extinction coefficient and $\beta$ the mean-beam length correction. The maximum burning rate per unit area, $\dot{m}_{\text {max }}^{\prime \prime}$, is also referred to in the literature by Babrauskas (1983) as $\dot{m}_{D \infty}^{\prime \prime}$, the mass burning rate for an infinite diameter pool. Average values of $\dot{m}_{D \infty}^{\prime \prime}$ and $k \beta$ for steady burning of more than 20 liquids and one solid (PMMA) are given in Babrauskas (1983). For heptane, $\dot{m}_{D \infty}^{\prime \prime}=0.101 \mathrm{~kg} \cdot \mathrm{m}^{-2} \cdot \mathrm{s}^{-1}$ and $k \beta=1.1 \mathrm{~m}^{-1}$, based on the experiments of Kung and Stavrianidis (1982) and Tarifa (1967). It is worth noting that Eq. (5) is valid for $D>0.2 \mathrm{~m}$, where heat transfer is dominated by radiation. As mentioned previously, Tewarson et al. (1981) experimentally studied the effect of oxygen on the pyrolysis rate. Their tests included heptane pool fires with a diameter of $0.1 \mathrm{~m}$ and oxygen concentrations ranging from 27.3 to $15.7 \%$.

The objective of this study is twofold: to better understand the effects of an oxygen-depleted atmosphere on the combustion of solid and liquid materials and to provide data needed to validate the numerical simulation tools of a fire. For this purpose, the calorimeter CADUCEE (Controlled Atmosphere Device for Unburnt and Carbon Emission Evaluation) was used. This calorimeter, designed and developed by IRSN (Institut de Radioprotection et de Sûreté Nucléaire), makes it possible to conduct experiments on solid, liquid or gaseous fuels at small and medium scales. This article is organized as follows: the experimental device is presented, as well as the associated metrology, the ignition procedure of the fuel is then detailed, the results obtained concerning the influence of ambient oxygen concentration on the combustion of horizontal PMMA slabs and heptane pools are finally analyzed and compared with those of the literature.

\section{DESCRIPTION OF EXPERIMENTS}

The experiments were conducted using the CADUCEE apparatus shown in Fig. 1. It is composed of a combustion chamber of $22 \mathrm{~m}^{3}$, with a height of $3.1 \mathrm{~m}$ and a diameter of $2.9 \mathrm{~m}$. This calorimeter has been developed by IRSN to simulate the depleted oxygen environments of a fully-developed fire, and even the fuel-rich postflashover fire environment. This was achieved using a nitrogen dilution of the incoming gases and a suitable flow rate through the combustion chamber. The air/nitrogen mixture is injected from the bottom of the combustion chamber (Fig. 1). The oxygen level of the oxidizing mixture is measured and controlled at three different positions in the combustion chamber. The upper part of the calorimeter is composed of an exhaust system, which recovers the combustion products before analyzing them in the test section. More details (metrology, estimation of measurement uncertainties) about the CADUCEE device can be found in Coutin et al. (2016).
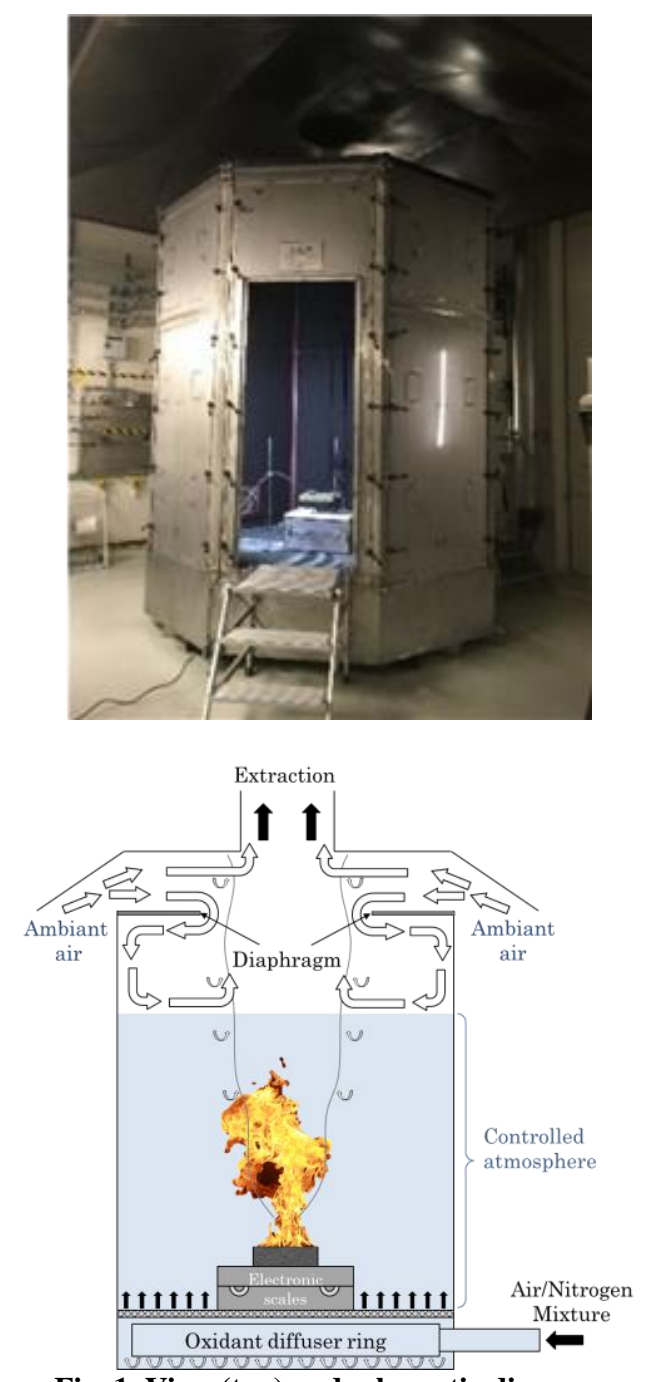

Fig. 1. View (top) and schematic diagram (bottom) of the CADUCEE calorimeter of IRSN.

Two fuels were chosen here: one is solid, the PMMA, the other liquid, heptane of technical quality. PMMA is often used to containment windows for glove boxes containing radioactive components in nuclear facilities. This "wellbehaved" polymer doesn't intumesce or produce char residues, and its thermo-physical properties are relatively well known. Heptane was chosen as liquid fuel, due to its high heat of combustion.

Solid fuel experiments were conducted on square slabs of PMMA with areas of 0.04, 0.16 and 0.36 $\mathrm{m}^{2}$ and thickness of $30 \mathrm{~mm}$. PMMA slabs were mounted horizontally on a steel support to avoid thermal deformations and covered with a steel screen to delimit the burning area (Fig. 2). One of the four lateral faces was initially polished to allow observation of the transient evolution of the PMMA regressing surface. The others were insulated with 50-mm-thick low emissivity foil-faced glass mineral wool batts to avoid any inopportune lateral ignition. To measure the total or radiative heat fluxes at the burning surface, a total heat flux sensor Medtherm 64-2-20T or an ellipsoidal radiometer Medtherm 64EP-2-21495T was embedded in a hole predrilled at the center of the slab. The gage face 


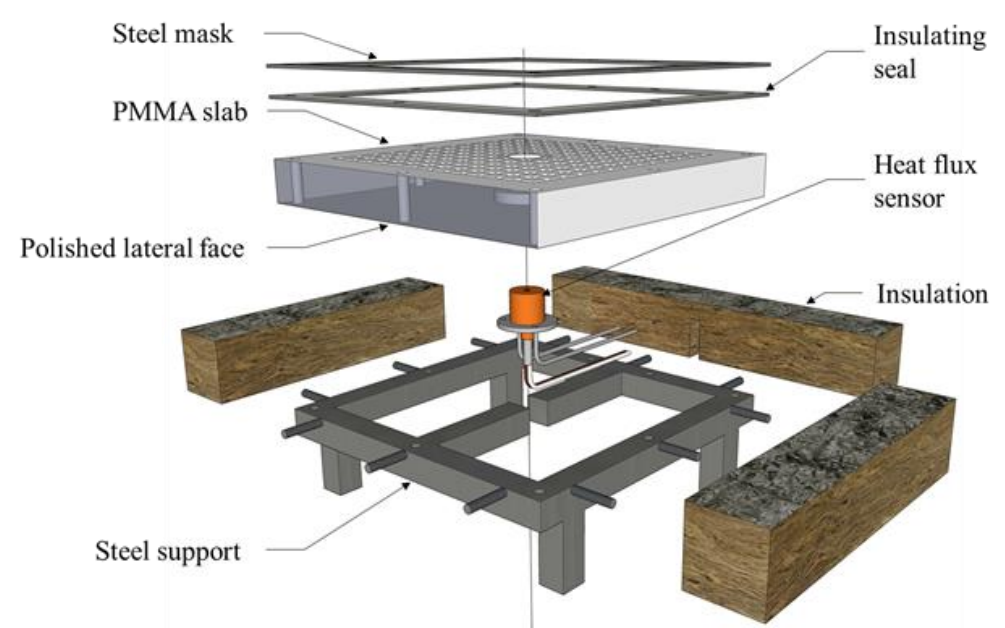

Fig. 2. Experimental setup for PMMA experiments.

was placed flush with the sample surface. This technique was also used by Rhodes and Quintiere (1996), Beaulieu and Dembsey (2008) and Pizzo et al. (2015). Both sensors were cooled with water at ambient temperature during the tests and a very low nitrogen flow (about $2 \mathrm{~L} \cdot \mathrm{min}^{-1}$ ) was used to avoid the entrance of soot particles into the ellipsoidal radiometer cavity.

Each experiment was performed twice, one to measure the radiative heat flux and one to measure the total heat flux. The experimental apparatus, including the support and the slab, was located on a Sartorius precision scale $( \pm 0.1 \mathrm{~g})$ to measure the time evolution of the sample mass. Gas temperatures were measured with an array of eleven K-type thermocouples of $1 \mathrm{~mm}$ diameter located, before ignition, at $0.05,0.1,0.15,0.2,0.3,0.4,0.5,1.0,1.5$, 2.0 , and $2.5 \mathrm{~m}$ from the upper face of the slab. The oxidizing flow rate was set to $1500 \mathrm{~m}^{3} \cdot \mathrm{h}^{-1}$ for slabs with areas of 0.04 and $0.16 \mathrm{~m}^{2}$, and to $2500 \mathrm{~m}^{3} \cdot \mathrm{h}^{-1}$ for $0.36-\mathrm{m}^{2}$ slabs. Smoke was exhausted at a rate of 2500,4000 , or $7000 \mathrm{~m}^{3} \cdot \mathrm{h}^{-1}$ for slabs with areas of $0.04,0.16$ and $0.36 \mathrm{~m}^{2}$, respectively. The initial fuel temperature was about $20^{\circ} \mathrm{C}$.

One of the major experimental challenges is to provide a homogeneous ignition of the solid upper face in the CADUCEE facility. The held solution consisted in grooving the upper surface of the slab and filling the 2-mm-deep grooves with a small amount of ethanol. A $21.0 \%$ oxygen concentration was kept during the ignition phase for a period depending on the slab size (i.e. 500, 900 and $1000 \mathrm{~s}$ for the slabs with areas of $0.04,0.16$ and $0.36 \mathrm{~m}^{2}$, respectively), ensuring that the ethanol was totally consumed (about $120 \mathrm{~s}$ ), the grooves had totally disappeared, the burning surface was plane, and the flame covered the whole surface. After that, the oxidizing mixture was injected into the combustion chamber at the desired level of oxygen. The extinction is provided by suddenly increasing the proportion of nitrogen into the oxidant flow to lower the oxygen concentration below $10.0 \%$. Qualification tests have highlighted a limiting oxygen concentration below which the flame extinction occurs. This concentration is about $17.5 \%$ for the PMMA regardless of the sample size.

This value is close to the literature values from different scale experiments (ISO 4589, (1996), Ebdon et al., 2000a and 2000b; Laachachi et al., 2005; Yang and Nelson, 2006, Zhubanov and Gibov, 1988; Price et al., 2002).

Heptane fuel was burned in two borosilicate glass containers (Table 1). The time evolution of the liquid fuel mass was measured using a Sartorius precision scales $( \pm 0.01 \mathrm{~g})$. Twelve K-type thermocouples of $1 \mathrm{~mm}$ diameter are positioned along the flame axis at $0.05,0.1,0.15,0.2,0.25$, $0.35,0.45,0.55,1.05,1.55,2.05$, and $2.55 \mathrm{~m}$ from the initial level of the liquid pool. For the largest pan, one thermocouple is added at $0.01 \mathrm{~m}$ from the pan bottom in order to measure the time evolution of the fuel temperature. The inlet oxidizing flow and exhaust flow rates were set to $1500 \mathrm{~m}^{3} \cdot \mathrm{h}^{-1}$ and $2500 \mathrm{~m}^{3} \cdot \mathrm{h}^{-1}$ respectively, and the initial fuel temperature was about $20^{\circ} \mathrm{C}$.

Ignition was provided with a propane burner. The $21 \%$ oxygen concentration was kept during $180 \mathrm{~s}$ ensuring a stable combustion. Qualification tests have shown a limiting oxygen concentration about $14.5 \%$ closed to the literature values (Loo et al. 2013; Fourneau, 2013).

Table 1 Fuel pan dimensions and initial liquid fuel height

\begin{tabular}{|c|c|c|c|}
\hline \multicolumn{3}{|c|}{ Pan } & \multirow[b]{2}{*}{$\begin{array}{l}\text { Fuel height, } \\
\text { mm }\end{array}$} \\
\hline $\begin{array}{c}\text { Internal } \\
\text { diameter, } \mathrm{mm}\end{array}$ & $\begin{array}{c}\text { Thickness, } \\
\text { mm }\end{array}$ & $\begin{array}{c}\text { Height, } \\
\text { mm }\end{array}$ & \\
\hline 196 & 3 & 20 & 17 \\
\hline 116 & 2 & 14 & 12 \\
\hline
\end{tabular}

\section{RESULTS AND DISCUSSION}

\subsection{Solid Fuel}

Table 2 summarizes PMMA burning results, along with the time periods for averaging. 
Table 2 PMMA experiment summary. $t_{i n j}$ corresponds to the instant at which the oxidizing mixture was injected at the desired oxygen level

\begin{tabular}{|c|c|c|c|c|c|c|c|}
\hline $\begin{array}{c}\text { Surface } \\
\text { area }\left(m^{2}\right)\end{array}$ & $\mathrm{X}_{2}$ & $t_{i n j}(s)$ & $\begin{array}{c}\text { Averaging } \\
\text { period }(s)\end{array}$ & $\begin{array}{c}\dot{m}\left(g . s^{-1}\right) \\
\pm 3 \%\end{array}$ & $\begin{array}{c}\dot{q}_{t}^{\prime \prime}\left(k W . m^{-2}\right) \\
\pm 4 \%\end{array}$ & $\begin{array}{c}\dot{q}_{r}^{\prime \prime}\left(k W . m^{-2}\right) \\
\pm 4 \%\end{array}$ & $\begin{array}{c}\dot{q}_{c}^{\prime \prime}\left(k W . m^{-2}\right) \\
\pm 4 \%\end{array}$ \\
\hline \multirow{5}{*}{0.04} & 0.21 & - & $2000-2200$ & 0.491 & 40.9 & 25.9 & 15.0 \\
\cline { 2 - 8 } & 0.20 & 500 & $2000-2200$ & 0.450 & 36.9 & 23.7 & 13.2 \\
\cline { 2 - 9 } & 0.19 & 500 & $2000-2200$ & 0.350 & 28.7 & 19.1 & 9.6 \\
\cline { 2 - 8 } & 0.18 & 500 & $2000-2200$ & 0.297 & 24.4 & 15.9 & 8.5 \\
\hline \multirow{5}{*}{0.16} & 0.21 & - & $1800-2000$ & 3.395 & 59.5 & 39.1 & 20.4 \\
\cline { 2 - 8 } & 0.20 & 900 & $1800-2000$ & 2.842 & 52.7 & 36.8 & 15.9 \\
\cline { 2 - 8 } & 0.19 & 900 & $1800-2000$ & 2.445 & 47.9 & 29.8 & 18.2 \\
\cline { 2 - 8 } & 0.18 & 900 & $1800-2000$ & 1.943 & 42.9 & 28.5 & 14.4 \\
\hline \multirow{5}{*}{0.36} & 0.21 & - & $1200-1600$ & 7.273 & - & - & - \\
\cline { 2 - 8 } & 0.20 & 1000 & $1200-1600$ & 6.898 & - & - & - \\
\cline { 2 - 8 } & 0.19 & 1000 & $1200-1600$ & 5.887 & - & - & - \\
\cline { 2 - 8 } & 0.18 & 1000 & $1200-1600$ & 5.370 & - & - & - \\
\hline
\end{tabular}

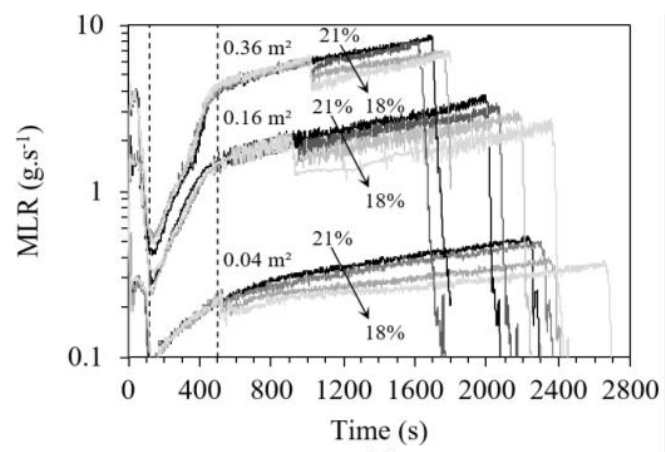

(a)

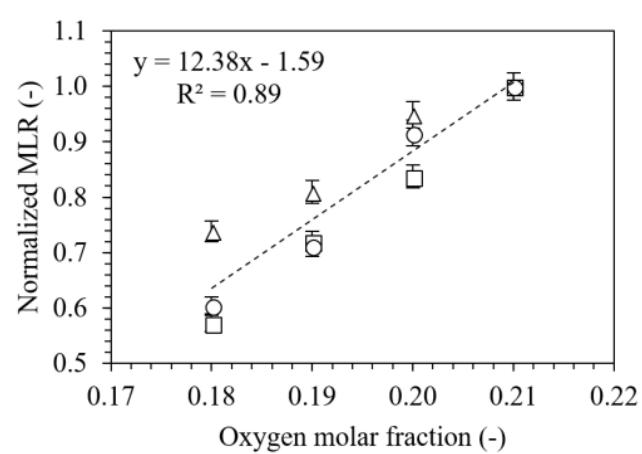

(b)

Fig. 3. (a) Time evolution of the MLR and (b) normalized MLR vs. oxygen molar fraction $\left(\bigcirc 0.04 \mathrm{~m}^{2}\right.$, $\left.\square 0.16 \mathrm{~m}^{2}, \triangle 0.36 \mathrm{~m}^{2}\right)$.

\subsubsection{Mass Loss Rate}

The MLR is calculated by deriving the time evolution of the sample mass and applying a 30-s moving centered average. Figure 3(a) shows the time evolution of the MLR for the three sample sizes and the four oxygen concentrations studied. Four periods can be observed: the first, from 0 to $120 \mathrm{~s}$, corresponds to ethanol combustion; the second, from 120 to $500 \mathrm{~s}$, to the time required for the flame to cover the upper face of the slab, which agrees with values obtained by Pizzo et al. (2015); and the third, from $500 \mathrm{~s}$, to PMMA burning until extinction.

During this period, an increase of the MLR can be observed. The bursting of bubbles leads to the formation of cavities that increases the specific area of the burning surface, which in turn leads to an increase of the total MLR and heat flux at the slab surface. Moreover, increasing the heat flux tends to increase the number of bubbles while reducing their size, contributing further to a rise in specific area (Kashiwagi and Ohlemiller, 1982; Marquis et al., 2014; Beaulieu, 2005). The fourth period corresponds to the extinction of the slab provided by an increase of nitrogen in the oxidizing mixture, leading to an oxygen concentration less than $10 \%$. As shown in Fig. 3(a), the higher the sample size, the higher the heat release rate and the heat feedback to the fuel surface, and thus the higher the
MLR. An average value of the MLR can be calculated over a period depending on the sample size (Table 2). This period corresponds to that when the MLR shows a nearly constant rate of change. The averaged mass loss rate values are then normalized with that obtained over the same period for an oxygen concentration of $21 \%$. As shown in Fig. 3(b), a linear correlation can be found between the normalized MLR per unit area and the oxygen molar fraction independently of the sample size as

$$
\frac{\dot{m}^{\prime \prime}}{\dot{m}_{21}^{\prime \prime}}=12.4 X_{O_{2}}-1.6
$$

\subsubsection{Gaz Temperature}

Figure 4(a) shows the time-averaged gas temperature versus the height measured from the initial fuel surface for the three sample sizes and a $21 \%$ ambient oxygen concentration. The three flame regions observed by McCaffrey (1979) are clearly identified. For example, for the smallest sample size, the persistent flame region is located between 0 and $0.2 \mathrm{~m}$ and the plume region above $1.1 \mathrm{~m}$, the intermittent flame region being located between the two. We can observe in Fig. 4(a) that the maximum value of the gas temperature and the height at which this maximum is obtained increase with the sample size. In addition, the larger the sample size, the slower the decrease in temperature. The maximum gas temperature is between 1080 and 
$1180 \mathrm{~K}$, in agreement with those obtained by Kacem et al. (2016) ( $1190 \mathrm{~K})$ for $0.01 \mathrm{~m}^{2}$ slabs and by Beaulieu and Dembsey (2008) (1184 \pm 100 $\mathrm{K})$ for $0.011 \mathrm{~m}^{2}$ slabs.

As expected, reducing the oxygen level leads to a decrease in maximum gas temperature for all sample sizes (Fig. 4(b)), as also observed by Santo and Tamanini (1981).

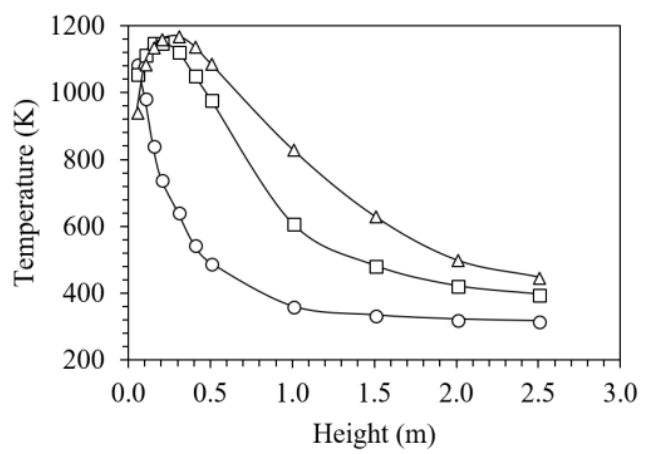

(a)

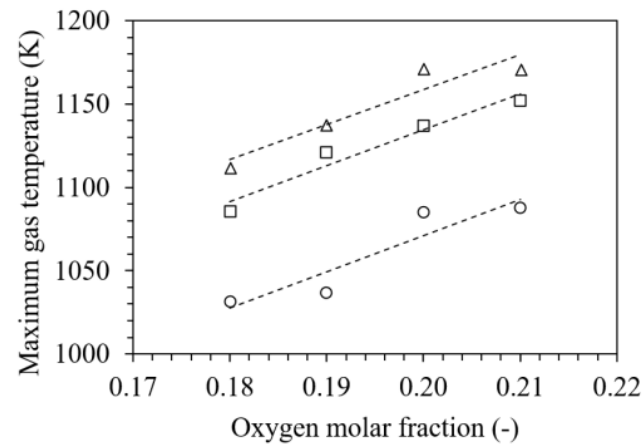

(b)

Fig. 4. (a) Gaz temperature vs. height for the $21 \%$ ambient oxygen concentration and (b) maximum gas temperature vs. oxygen molar fraction $\left(\bigcirc 0.04 \mathrm{~m}^{2}, \square 0.16 \mathrm{~m}^{2}, \triangle 0.36 \mathrm{~m}^{2}\right)$.

\subsubsection{Heat Flux}

As mentioned above, total and radiative heat fluxes were measured at the center of the slab using a total heat flux sensor and an ellipsoidal radiometer. The convective heat flux was calculated as the difference between the total heat flux and the radiative heat flux. Table 2 gives the averaged values of heat fluxes versus the oxygen concentration for the slabs with areas of 0.04 and $0.16 \mathrm{~m}^{2}$. Measurements were not possible for larger slabs due to problems of condensation of MMA and/or liquid PMMA projections on the sensitive surface of the sensors.

It is obvious that the total heat flux increases with the sample size and oxygen concentration. For all experiments, radiation dominates. Normalized by the values obtained for the $21 \%$ ambient oxygen concentration, the total and radiative heat fluxes are plotted as a function of the oxygen concentration in Fig. 5. As observed for the MLR, a linear decrease of the normalized heat fluxes with the oxygen molar fraction can be observed. What is more surprising is that the contribution of radiation to the total heat flux remains almost constant, with approximately $65 \%$, leading to a convective contribution of about $35 \%$ (Fig. 6).

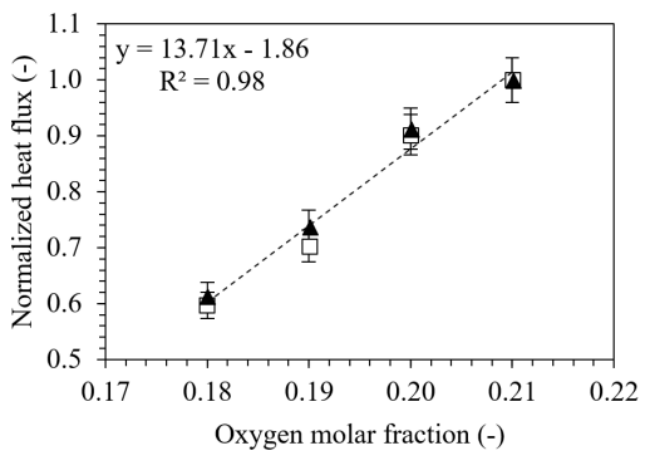

(a)

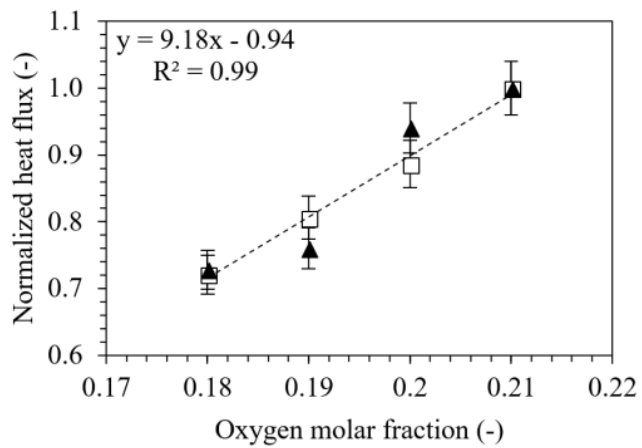

(b)

Fig. 5. Normalized heat fluxes versus oxygen molar fraction for samples of (a) $0.04 \mathrm{~m}^{2}$ and (b) $0.16 \mathrm{~m}^{2}$ ( $\square$ Total, $\Delta$ Radiative).

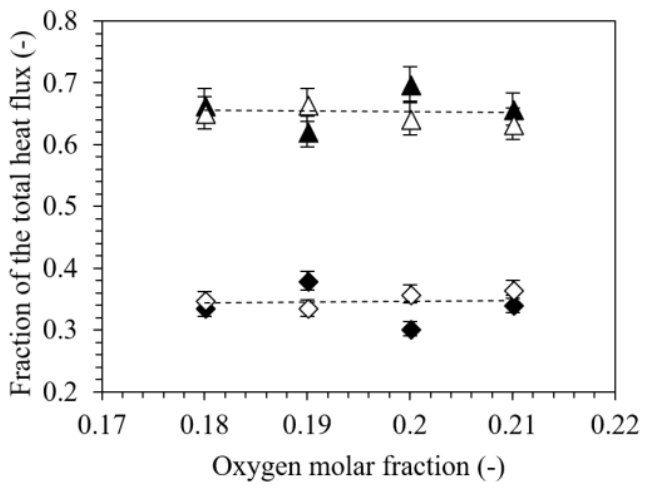

Fig. 6. Radiative and convective contributions to the total heat flux versus oxygen molar fraction for samples of $0.04 \mathrm{~m}^{2}$ ( $\Delta$ Radiative fraction, Convective fraction) and $0.16 \mathrm{~m}^{2}(\triangle$ Radiative fraction, $\diamond$ Convective fraction).

\subsection{Liquid fuel}

Table 3 summarizes heptane burning results, along with the time periods for averaging.

\subsubsection{Pyrolysis Mass Loss Rate}

Figure 7(a) shows the time evolution of the MLR for the $0.011-\mathrm{m}^{2}$ and $0.03-\mathrm{m}^{2}$ heptane pools and ambient oxygen concentrations ranging from 15 to $21 \%$. From 0 to $180 \mathrm{~s}$, fire develops in a $21 \%$ ambient oxygen concentration. Subsequently, a 
quasi-steady burning period is observed before flame extinction due to fuel depletion. As done previously, a more general approach may be used by averaging the MLR over the steady-burning period (Table 3) and normalizing the time-averaged value with the MLR that results from burning in normal oxygen concentrations (Fig. 7 (b)).

Table 3 Heptane experiment summary. $t_{i n j}$ corresponds to the instant at which the oxidizing mixture was injected at the desired oxygen level.

\begin{tabular}{|c|l|c|c|c|}
\hline $\begin{array}{c}\text { Pool area } \\
\left(m^{2}\right)\end{array}$ & $X_{O_{2}}$ & $\begin{array}{c}t_{\text {inj }} \\
(s)\end{array}$ & $\begin{array}{c}\text { Averaging } \\
\text { period }(s)\end{array}$ & $\begin{array}{c}\dot{m}\left(g . s^{-1}\right) \\
\pm 3 \%\end{array}$ \\
\hline \multirow{4}{*}{0.011} & 0.21 & - & $300-590$ & 0.156 \\
\cline { 2 - 5 } & 0.19 & 180 & $300-590$ & 0.130 \\
\cline { 2 - 5 } & 0.17 & 180 & $300-590$ & 0.108 \\
\cline { 2 - 5 } 0.030 & 0.15 & 180 & $800-1000$ & 0.079 \\
\hline \multirow{4}{*}{0.21} & - & $300-730$ & 0.495 \\
\cline { 2 - 5 } & 0.19 & 180 & $300-730$ & 0.401 \\
\cline { 2 - 5 } & 0.17 & 180 & $300-730$ & 0.323 \\
\cline { 2 - 5 } & 0.15 & 180 & $300-730$ & 0.271 \\
\hline
\end{tabular}

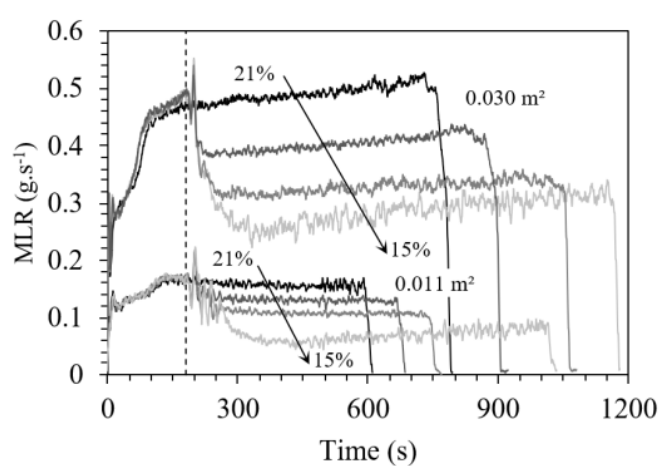

(a)

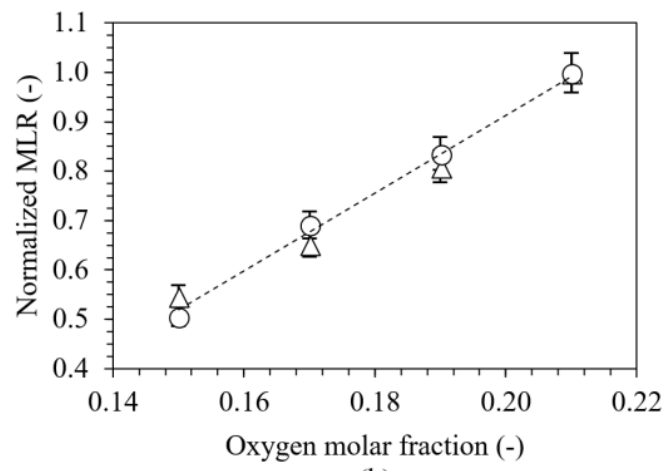

(b)

Fig. 7. (a) Time evolution of MLR and (b) normalized MLR versus oxygen molar fraction ( $\mathrm{O} .011 \mathrm{~m}^{2}, \triangle \mathbf{0 . 0 3 0} \mathbf{~ m}^{2}$ ).

Although there is little data, a linear decrease of the normalized MLR with the oxygen concentration can be observed

$$
\frac{\dot{m}^{\prime \prime}}{\dot{m}_{21}^{\prime \prime}}=7.9 X_{O_{2}}-0.7
$$

\subsubsection{Gas Temperatures}

Figure 8(a) shows the evolution of the timeaveraged raw gas temperature (without radiation correction) with height (measured from the initial pool level) in a $21 \%$ oxygen concentration for heptane pools with areas of 0.011 and $0.030 \mathrm{~m}^{2}$. The three flame regions observed by McCaffrey (1979) are clearly identified and the maximum flame temperatures are nearly the same, around $1030 \mathrm{~K}$, which can be favorably compared with that obtained by Chen et al. (2012) for a $0.031-\mathrm{m}^{2}$ heptane pool fire, with $973 \mathrm{~K}$. As shown in Fig. 8 (b), the maximum gas temperature increases with the oxygen concentration, and this effect is more pronounced for the smaller pool size. It can be clearly seen from Fig. 9 that the visible flame height increases with the pool size and oxygen concentration, because of an increase in MLR (Fig. $7(a))$.

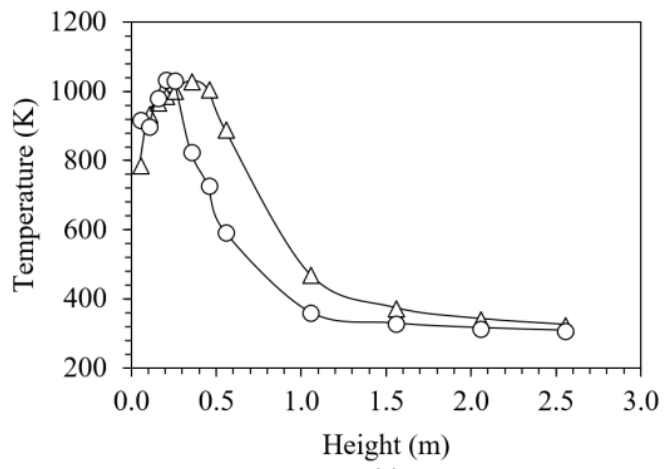

(a)

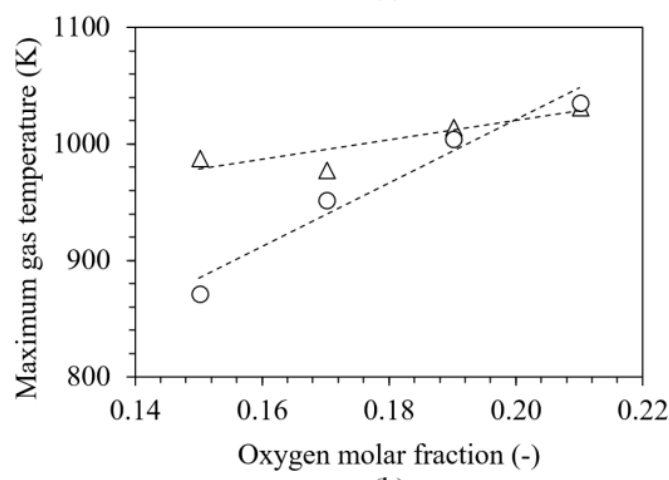

(b)

Fig. 8. (a) Gaz temperature vs. height in a $21 \%$ oxygen concentration and (b) maximum gas temperature vs. oxygen molar fraction $(O 0.011$ $\left.\mathrm{m}^{2}, \triangle \mathbf{0 . 0 3 0} \mathrm{m}^{2}\right)$.

\subsubsection{Fuel Temperature}

Figure 10 shows the time evolution of the liquid temperature at $1 \mathrm{~cm}$ from the container bottom for the $0.030-\mathrm{m}^{2}$ heptane pool fire and for the four oxygen molar fractions considered. It is important to note that no boiling has been observed. In a $21 \%$ oxygen concentration, an increase of the fuel temperature can be observed up to a value close to the boiling temperature $(371.3 \mathrm{~K})$ when the burning surface is just above the thermocouple. When the interface reaches the thermocouple location, a slight decrease followed by a plateau is observed. Subsequently, the thermocouple is in the hot gas layer just above the interface, which explains the 


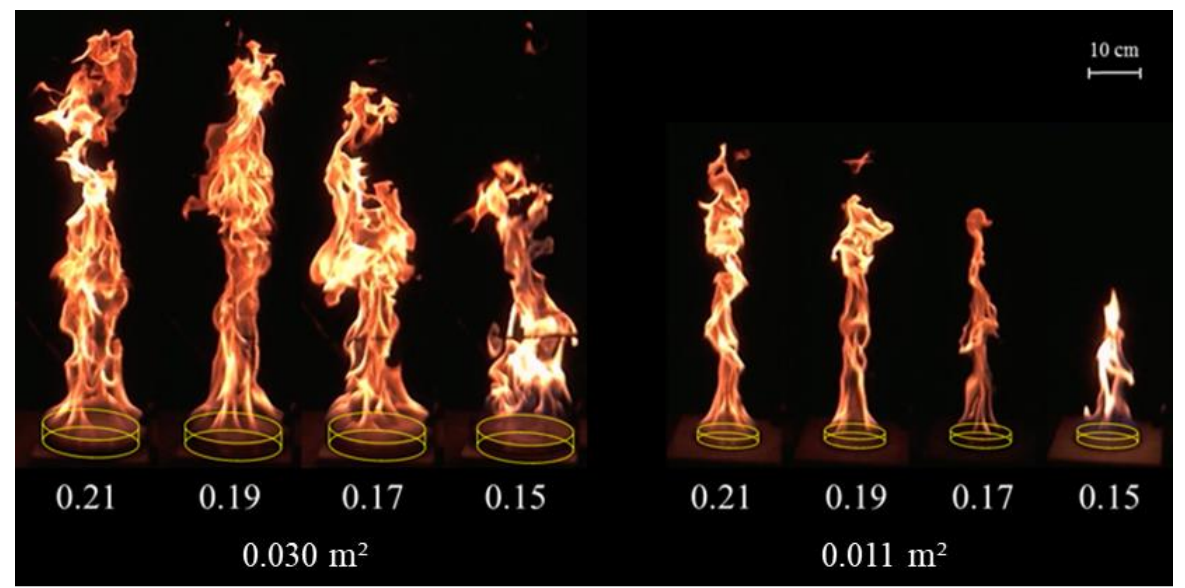

Fig. 9. Snapshots of 0.030 and $0.011 \mathrm{~m}^{2}$ heptane pool fires for oxygen concentrations in the range of 15 $21 \%$.

sharp increase in temperature, up to $415-425 \mathrm{~K}$. This is followed by a slight increase when the flame gets closer to the flame. Finally, a second sharp increase is observed when the thermocouple is in the flame region. Current results are comparable to those found by Chen et al. (2012), namely $371.8 \mathrm{~K}$ for the boiling temperature and $403-418 \mathrm{~K}$ for the hot gases.

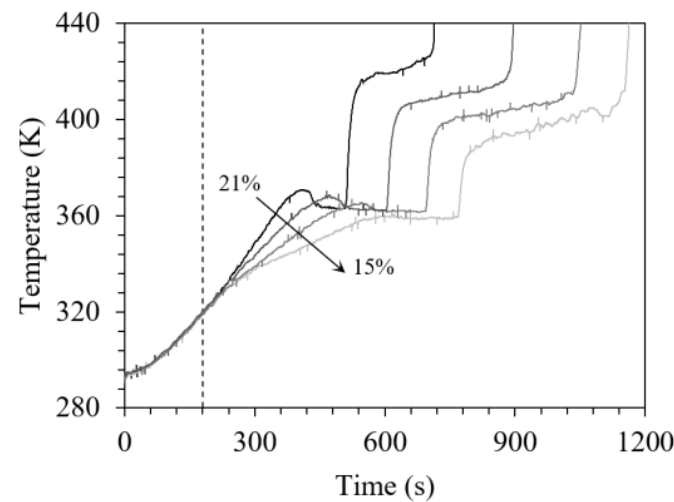

Fig. 10. Time evolution of the liquid temperature at $1 \mathrm{~cm}$ from the container bottom for the 0.030 $\mathrm{m}^{2}$ heptane pool fire and oxygen concentration in the range of $15-21 \%$.

As the oxygen molar fraction decreases, the same trend is observed, but with lower temperature levels. For example, the plateau temperature decreases by about $10 \mathrm{~K}$ as the ambient oxygen concentration is decreased from 21 to $15 \%$. This general comportment can be explained by a decrease of the heat transfers at the fuel surface and inside the fuel. Further work is required to assess this statement.

\section{COMPARISON LITERATURE RESULTS}

WITH

Figure 11 shows some literature results on the MLR of liquid fuels as a function of the pan diameter at $21 \%$ ambient oxygen concentration. A large scatter is observed that can be attributed to several factors, such as the geometry of the container, the nature of the material that constitutes it (e.g. steel, stainless steel or borosilicate glass) the quality of heptane (technical or pure) (Loo et al., (2016), the environmental conditions (e.g. ambient temperature or ventilation) or the lip height. Despite this, the results obtained in the present study are in good agreement with those of literature.

Regarding the effect of oxygen on the burning rate, Fig. 12 gives a comparison of the current results with the literature data. Included are data from experiments with different fuel types and fuel sizes. The use of normalized MLR allows relevant comparison. Good agreement is generally found, as well as with the empirical correlation of Peatross and Beyler (see Eq. (4)). One of the reasons for this good concordance may be that this correlation was obtained in conditions for which external heat fluxes were negligible, as is the case for small and moderate fire experiments in CADUCEE (i.e. heat release rate typically less than $250 \mathrm{~kW}$ ).

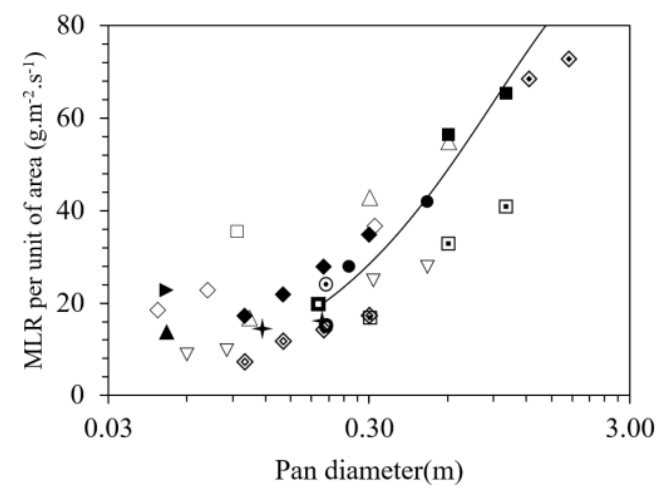

Fig. 11. MLR per unit of area versus pan diameter in $21 \%$ ambient oxygen concentration. Symbols: $\square$ Tewarson et al. (1981),

- Babrauskas correlation (1983), $\diamond$ Kung and Stavrianidis (1982), • Tarifa (1967), @ Chen et al. (2012), $\odot$ Chen et al. (2012), $\square$ Loo et al. (2016), \ Hayasaka (1997), Hayasaka (1997),

$\nabla$ Mulholland et al. (1989), $\square$ Koseki and Yumoto (1988), $\diamond$ Gore et al. (1991), $\triangle$ Buch et al. (1997), $\square$ Klassen and Gore (1994), $\diamond$ Kang et al. (2010), Kang et al. (2010), + CADUCEE (present study)). 


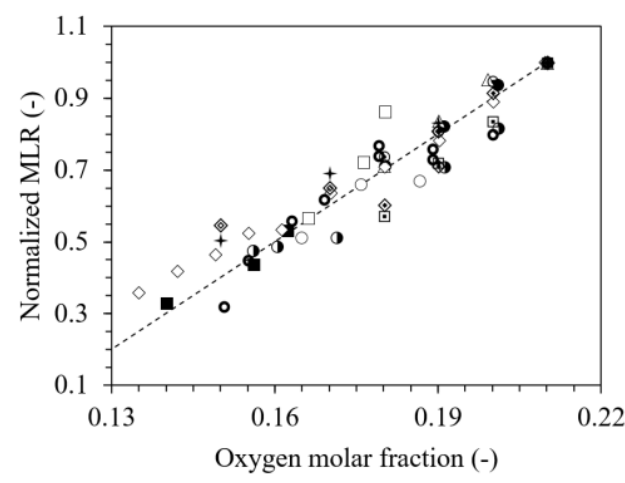

Fig. 12. Normalized MLR versus oxygen molar fraction. Comparison between current results: + Heptane $-0.011 \mathrm{~m}^{2}, \diamond$ Heptane $-0.030 \mathrm{~m}^{2}$, $\diamond$ PMMA - $0.04 \mathrm{~m}^{2}$, 口 PMMA - $0.16 \mathrm{~m}^{2}$, $\odot$ PMMA - $0.36 \mathrm{~m}^{2}$. Comparison with literature result: $\square$ Peatross and Beyler (1997) - Diesel $0.3 \mathrm{~m}^{2}, \square$ Peatross and Beyler (1997) - Diesel $0.5 \mathrm{~m}^{2}$, --- Peatross and Beyler correlation (1997) - Eq. (4), O Tewarson et al. (1981) - PMMA $0.073 \mathrm{~m}^{2}$, Tewarson et al. (1981) - PMMA $0.068 \mathrm{~m}^{2}$, T Tewarson et al. (1981) - Heptane $0.0068 \mathrm{~m}^{2}, \triangle$ Santo and Tamanini (1981) PMMA - 0.07 m², O Coutin et al. (2016) Heptane - $0.07 \mathrm{~m}^{2}, \diamond$ Brohez et al. (2008) Pyridine $-0.0061 \mathrm{~m}^{2}$.

\section{CONCLUSION}

The controlled-atmosphere calorimeter CADUCEE of IRSN was used to study the effect of ambient oxygen concentration on the burning behavior of solid (PMMA) and liquid (heptane) fuels. Square slabs of clear PMMA with areas of 0.04, 0.16 and $0.36 \mathrm{~m}^{2}$ and heptane pools with areas of 0.011 and $0.030 \mathrm{~m}^{2}$ were used. Oxygen concentration varied from 18 to $21 \%$ for PMMA, and from 15 to $21 \%$ for heptane. From the results, some conclusions can be drawn:

- Current data on time-averaged normalized MLR, heat flux, and flame temperature are in good agreement with those reported in the literature.

- The normalized MLR linearly decreases with the oxygen concentration, with a slope of 12.4 for PMMA and 7.9 for heptane, compared to a slope of 10.0 for the Peatross and Beyler correlation.

- Reducing the oxygen level leads to a decrease in the flame height and of the maximum flame temperature for both fuels, whatever the sample size;

- For heptane pool fires, temperature measurements in the liquid layer reveal a decrease in heat transfers at the fuel surface and inside the fuel with the oxygen molar fraction.

- Although the total and radiative heat fluxes measured at the center of the PMMA slabs decrease with the oxygen concentration, the radiative and convective contributions to the total heat flux remain almost constant, with about $65 \%$ and $35 \%$ respectively, regardless of sample size and oxygen concentration.

In the continuity of this study, further work is in progress first, to collect additional data on heptane pool fires; second, to evaluate the flame heat feedback to the burning surface of liquid pools, using borosilicate glass pans that are specifically designed to insert a heat flux sensor at the center of the pool.

\section{REFERENCES}

Babrauskas, V. (1983). Estimating large pool fire burning rates. Fire Technology 19, 251-261.

Beaulieu, P. (2005). Flammability characteristics at heat flux levels up to $200 \mathrm{~kW} \cdot \mathrm{m}^{-2}$ and the effect of oxygen on flame heat flux. Ph. D. thesis, Worcester Polytechnic Institute.

Beaulieu, P. A. and N. A. Dembsey (2008). Effect of oxygen on flame heat flux in horizontal and vertical orientations. Fire Safety Journal 43(6), 410-428.

Brohez, S., G. Marlair and C. Delvosalle (2008). The effect of oxygen concentration on $\mathrm{CO}$ and soot yields in fires. Fire and Materials 32(3), 141-158.

Buch, R., A. Hamins, K. Konishi, D. Mattingly and T. Kashiwagi (1997). Radiative emission fraction of pool fires burning silicone fluids. Combustion and Flame 108, 118-126.

Chen, B., S. Lu, C. Li, Q. Kang and M. Yuan (2012). Unsteady burning of thin-layer pool fires. Journal of Fire Sciences 30, 3-15.

Chen, X., J. Liu, Z. Zhou, P. Li, T. Zhou, D. Zhou and J. Wang (2015). Experimental and theoretical analysis on lateral flame spread over inclined PMMA surface. International Journal of Heat and Mass Transfer 91, 68-76.

Coutin, M., D. Alibert and B. Porterie (2016). Intermediate-scale controlled-atmosphere calorimeter CADUCEE. Proceedings of the Fourteenth International Conference on Fire Science and Engineering, INTERFLAM, 1433-1444.

Drysdale, D. D. and A. J. R. Macmillan (1992). Flame spread on inclined surfaces. Fire Safety Journal 18, 245-254.

Ebdon, J.R., B.J. Hunt, P. Joseph, C.S. Konkel, D. Price, K. Pyrah, T.R. Hull, G.J. Milnes, S.B. Hill, C.I. Lindsay, J. McCluskey, I. Robinson (2000a). Thermal degradation and flame retardance in copolymers of methyl methacrylate with diethyl (methacryloyloxymethyl) phosphonate. Polymer Degradation and Stability 70(3), 425436.

Ebdon, J. R., D. Price, B. J. Hunt, P. Joseph, F. 
Gao, G. J. Milnes, L. K. Cunliffe (2000b). Flame retardance in some polystyrenes and poly(methyl methacrylate)s with covalently bound phosphorus-containing groups: initial screening experiments and some laser pyrolysis mechanistic studies. Polymer Degradation and Stability 69, 267-277.

Fourneau, C. (2013). Etude de feux de substances chimiques en conditions sous-ventilées à l'aide d'un cône calorimètre. Ph. D. thesis, Université de Mons.

Gollner, M. J., X. Huang, J. Cobian, A. S. Rangwala and F. A. Williams (2013). Experimental study of upward flame spread of an inclined fuel surface. Symposium (International) on Combustion 34(2), 25312538.

Gore, J., M. Klassen, A. Hamins and T. Kashiwagi (1991). Fuel property effects on burning rate and radiative transfer from liquid pool flames. Fire Safety Science - Proceedings of the Third International Symposium 395-404.

Hayasaka, H. (1997). Unsteady burning rates of small pool fires. Fire Safety Science Proceedings of the Fifth International Symposium 499-510.

ISO 4589, Plastics (1996). Determination of burning behaviour by oxygen index, International Organization for Standardization, Geneva.

Kacem, A., M. Mense, Y. Pizzo, G. Boyer, S. Suard, P. Boulet, G. Parent and B. Porterie (2016). A fully coupled fluid/solid model for open air combustion of horizontally-oriented PMMA samples. Combustion and Flame 170, 135-147.

Kang, Q., S. Lu and B. Chen (2010). Experimental study on burning rate of small scale heptane pool fires. Chinese Science Bulletin 55, 973979.

Kashiwagi, T. and T. J. Ohlemiller (1982). A study of oxygen effects on nonflaming transient gasification of PMMA and PE during thermal irradiation. Symposium (International) on Combustion 19(1), 815-823.

Klassen, M. and J. P. Gore (1994). Structure and radiation properties of pool fires. NIST Report GCR-94-651, National Institute of Standards and Technology.

Koseki, H. and T. Yumoto (1988). Air entrainment and thermal radiation from heptane pool fires. Fire Technology 24(1), 33-47.

Kung, H. C. and P. Stavrianidis (1982). Buoyant plumes of large-scale pool fires. Symposium (International) on Combustion 19(1), 905-912.

Laachachi, A., M. Cochez, M. Ferriol, J. M. LopezCuesta and E. Leroy (2005). Influence of TiO2 and $\mathrm{Fe} 2 \mathrm{O} 3$ fillers on the thermal properties of poly(methyl methacrylate) (PMMA). Materials Letters 59, 36-39.
Linteris, G., L. Gewuerz, K. Mcgrattan and G. Forney (2005). Modeling Solid Sample Burning. Fire Safety Science 8, 625-636.

Loo, A. S. X., A. Coppalle, P. Aîné (2013). Flame extinction in a ventilation-controlled compartment. Proceedings of the Ninth AsiaOceania Symposium on Fire Science and Technology 62, 301-308.

Loo, A. S. X., A. Coppalle, J. Yon and P. Aîné (2016). Time-dependent smoke yield and mass loss of pool fires in a reduced-scale mechanically ventilated compartment. Fire Safety Journal 81, 32-43.

Marquis, D., E. Guillaume and A. Camillo (2014). Effects of oxygen availability on the combustion behaviour of materials in a controlled atmosphere cone calorimeter. Fire Safety Science - Proceedings of the Eleventh International Symposium 138-151.

McCaffrey, B. (1979). Purely buoyant diffusion flames: some experimental results, National Bureau of Standards.

Mulholland, G., V. Henzel and V. Babrauskas (1989). The effect of scale on smoke emission. Fire Safety Science - Proceedings of the Second International Symposium 347-357.

Nasr, A., S. Suard, H. El-Rabii, L. Gay and J. P. Garo (2011). Fuel mass-loss rate determination in a confined and mechanically ventilated compartment fire using a global approach. Combustion Science and Technology 183(12), 1342-1359.

Peatross, M. and C. Beyler (1997). Ventilation effects on compartment fire characterization. Fire Safety Science - Proceedings of the Fifth International Symposium 403-414.

Pizzo, Y., C. Lallemand, A. Kacem, A. Kaiss, J. Gerardin, Z. Acem, P. Boulet and B. Porterie (2015). Steady and transient pyrolysis of thick clear PMMA slabs. Combustion and Flame $162,226-236$.

Pizzo, Y., J. L. Consalvi, P. Querre, M. Coutin and B. Porterie (2009). Width effects on the early stage of upward flame spread over PMMA slabs: Experimental observations. Fire Safety Journal 44(3), 407-414.

Price, D., K. Pyrah, T. R. Hull, G. J. Milnes, J. R. Ebdon, B. J. Hunt and P. Joseph (2002). Flame retardance of poly (methyl methacrylate) modified with phosphorus-containing compounds. Polymer Degradation and Stability 77(2), 227-233.

Quintiere, J. G. and A. S. Rangwala (2004). A theory for flame extinction based on flame temperature. Fire and Materials 28 (5), 387402.

Rhodes, B. T. and J. G. Quintiere (1996). Burning rate and flame heat flux for PMMA in a cone calorimeter. Fire Safety Journal 26(3), 221240. 
D. Alibert et al. /JAFM, Vol. 12, Special Issue, pp. 37-47, 2019.

Santo, G. and F. Tamanini (1981). Influence of oxygen depletion on the radiative properties of PMMA flames. Symposium (International) on Combustion 18(1), 619-631.

Tarifa, C.S. (1967). Open fires, Instituto Nacional de Tecnica Aeroespacial Esteban Terradas, Madrid, 1967.

Tewarson, A. and R. F. Pion (1976). Flammability of plastics - I Burning intensity. Combustion and Flame 26, 85-103.

Tewarson, A., J. L. Lee and R.F. Pion (1981). The influence of oxygen concentration on fuel parameters for fire modeling. Symposium (International) on Combustion 18(1), 563-570.

Utiskul, Y., J. G. Quintiere, A. S. Rangwala, B. A. Ringwelski, K. Wakatsuki and T. Naruse
(2005). Compartment fire phenomena under limited ventilation. Fire Safety Journal 40(4), 367-390.

Yang, F. and G. L. Nelson (2006). Polymer/silica nanocomposites prepared via extrusion. Polymers for Advanced Technologies 17(4), 320-326.

Zabetakis, M. G. and D. S. Burgess (1961). "Research on Hazards Associated with the Production of and Handling of Liquid Hydrogen," U.S. Bureau of Mines Report, RI 5705.

Zhubanov, T. B. and K. M. Gibov (1988). Oxygen index and minimum limiting rates of polymer combustion. Fire and Materials 12(4), 169172. 